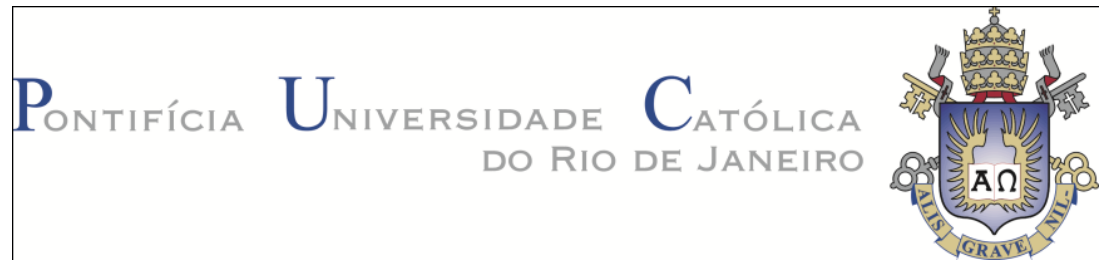

\title{
Concepção de um triciclo omnidirectional
}

\section{Design of an omnidirectional tricycle}

Mariana da Rocha Osborne

Autora

Prof. Mauro Speranza Neto

Orientador

Prof. Jorge Luiz Fontanella

Co-orientador

Rio de Janeiro, 03 de Dezembro de 2015 


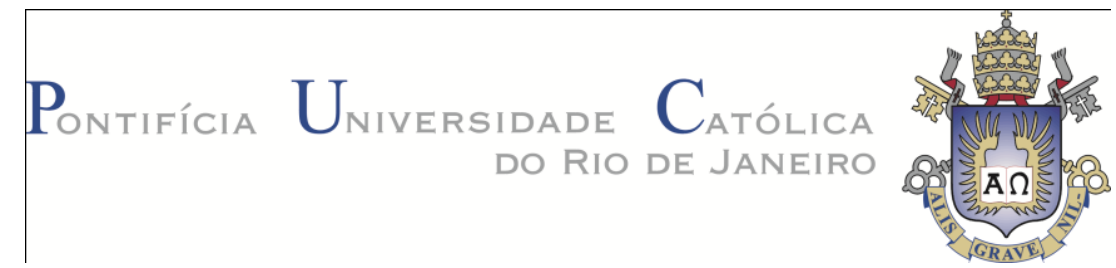

\section{Concepção de um triciclo onmidirecional}

O presente trabalho como requisito parcial para obtenção do grau de Engenheira Mecânica Departamento de Engenharia Mecânica do Centro Técnico Científico da PUC-Rio.

Mariana da Rocha Osborne Autora

Prof. Mauro Speranza Neto

Orientador

Prof. Jorge Luiz Fontanella

Co-orientador

Departamento de Engenharia Mecânica - PUC-Rio

Prof. Marcelo de Andrade Dreux Coordenador do Departamento de Engenharia Mecânica - PUC-Rio

Rio de Janeiro, 03 de Dezembro de 2015 


\section{Agradecimentos:}

Meus sinceros agradecimentos aos meus familiares, especialmente meus pais, que me apoiaram durante toda essa jornada. Agradeço aos queridos orientador Mauro Speranza e coorientador Jorge Fontanella pelo apoio na produção desse trabalho. Aos amigos Rodrigo Neumann, Gabriela Martins, Letícia Nicolino e Tamires Lucas pelo companherismo, e ao meu namorado Gustavo Vilar pelo amor e compreensão. Agradeço principalmente aos professores que foram essenciais a minha formação acadêmica e pessoal. 


\section{Resumo:}

O presente projeto consiste na concepção de um triciclo omnidirecional autonomo que tem como finalidade o transporte de cargas em um ambiente de armazenamento. O veículo em questão será munido de um sistema de atuação, elementos de controle e um sistema de sensoriamento, para possibilitar sua navegação em um ambiente previamente estudado.

Palavras-chave: Veículo autonomo; omnidirecional; AGV 


\title{
Design of an omnidirectional tricycle
}

\begin{abstract}
:
The current project consists in the design of an omnidirectional autonomous tricycle, whose purpose is transporting charge into a storage environment. The vehicle in question will be provided with an actuation system, control elements and a sensing system for enabling it's way through a previously studied environment.
\end{abstract}

Keywords: omnidirection; autonomous vehicle; AGV 


\section{Sumário}

ÍNDICE DE FIGURAS: ................................................................................................... VII

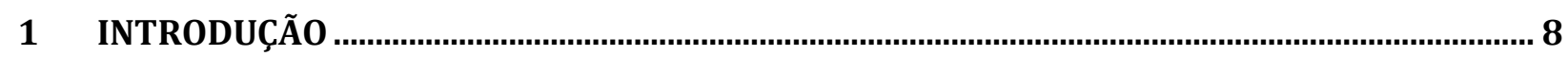

2 DESENVOLVIMENTO _......................................................................................................11

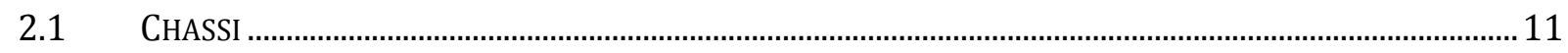

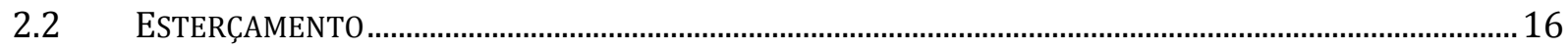

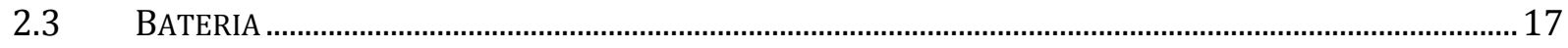

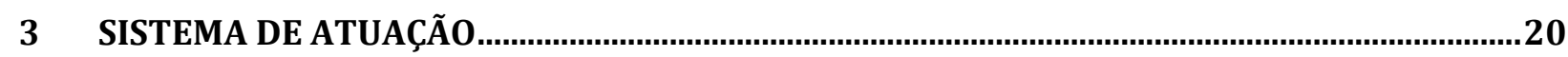

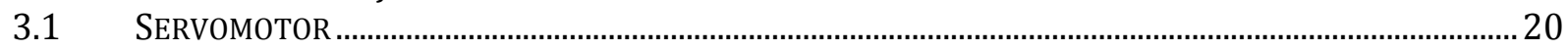

3.2 MOTOR NAS RODAS...............................................................................................................................21

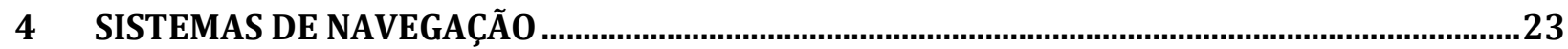

4.1 PoSICIONAMENTO RELATIVO..............................................................................................................................23

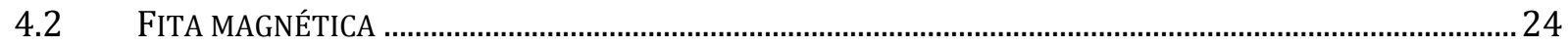

4.3 PoNTOS DE REFERÊNCIA MAGNÉTICOS ...........................................................................................2

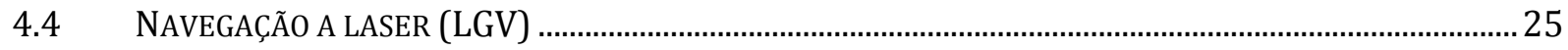

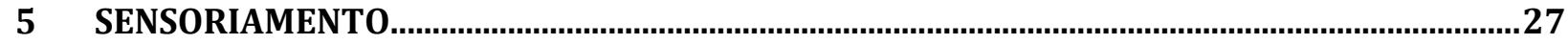

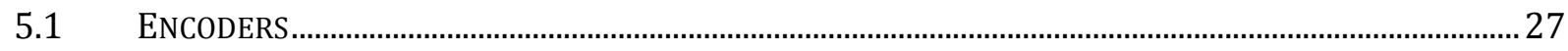

5.1.1 Encoder Incremental........................................................................................................................2 29

5.1.2 Encoder Absoluto ..........................................................................................................................29

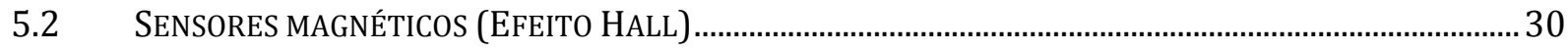

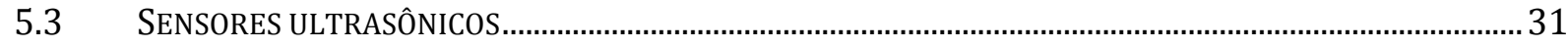

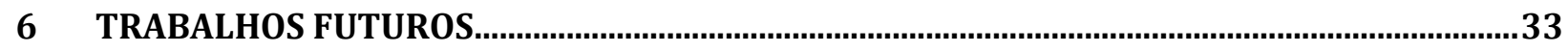

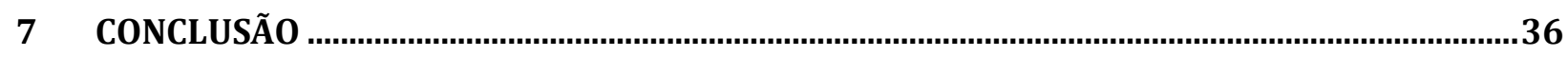

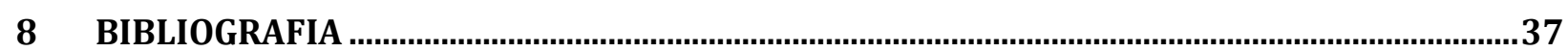




\section{Índice de figuras:}

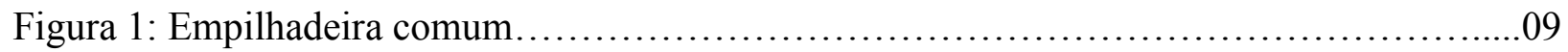

Figura 2: Chassi 3D................................................................

Figura 3: Vistas do chassi.......................................................... 14

Figura 4: Centro de massa do chassi................................................. 15

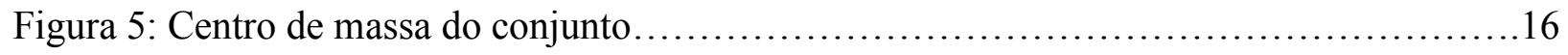

Figura 6: Vista 3D do conjunto....................................................

Figura 7: Montagem dos componentes de roda......................................... 18

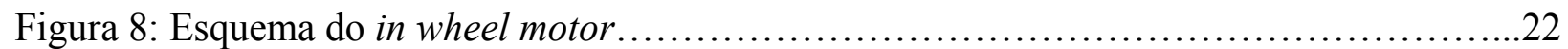

Figura 9: Sistema de navegação a laser.................................................26

Figura 10: Esquema de um encoder............................................... 28

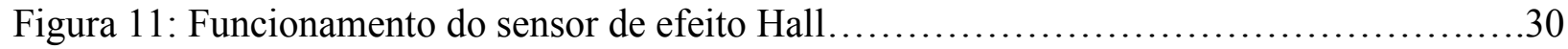

Figura 12: Exemplo real do ângulo de alcance do sensor ultrassônico.........................32 


\section{Introdução}

Atualmente percebe-se uma evolução muito acentuada nos meios de produção e nas áreas tecnológicas. As exigências dos últimos anos vêm abrindo espaço para que haja cada vez mais a automação dos processos de produção, que é uma solução para as principais preocupações no meio industrial, como a alta produtividade o baixo custo. Complementando essas atividades, a automação dos centros de armazenamento e de distribuição de materiais e produtos também vem sendo cada vez mais importante no cenário atual da indústria.

O transporte de cargas é essencial para diversas atividades humanas e por isso é fundamental que este seja feito da maneira mais eficiente possível. As empilhadeiras comumente utilizadas para esse serviço parecem carecer da sua potencial eficiência pelos principais fatores: Necessidade de um condutor, introduzindo erros humanos e possíveis acidentes; e a dificuldade de manobra dos veículos, aumentando o tempo de realização da tarefa. Uma possível solução para essas questões é a utilização de AVGs (automatic guided vehicle), que é um veículo guiado automaticamente, ou seja, sem a necessidade de um condutor. Sua utilização tem como motivação a redução de custos operacionais e aumentar a eficiência da logística industrial. Esse tipo de veículo para o transporte de materiais têm diversas vantagens em relação aos veículos convencionais, tais como:

1. Não há necessidade de um condutor

2. Ambientalmente responsável

3. Fácil adaptação a mudanças no ambiente.

4. Aumento na eficiência do transporte 
5. Segurança caso haja circulação de pessoas

Tendo em vista as questões comentadas acima, a discussão de uma solução para tais problemas pode ser útil para empreendimentos futuros. A aplicação de um veículo omnidirecional e autônomo para o transporte de cargas é uma solução que acabaria com os principais fatores que provocam a ineficiência dessa tarefa e assim se dá a relevância do estudo que será feito nesse trabalho.

Dois projetos finais que foram elaborados podem complementar o estudo que será feito nesse trabalho. Apesar de não terem sido feito em conjunto, pode-se dizer que todos abordam aspectos diferentes de uma mesma idéia. Abaixo serão feitos breves comentários acerca desses dois projetos, um de Rodrigo Neumann e outro de Thais Joffe, e se mostrará como eles podem se relacionar com o presente trabalho.

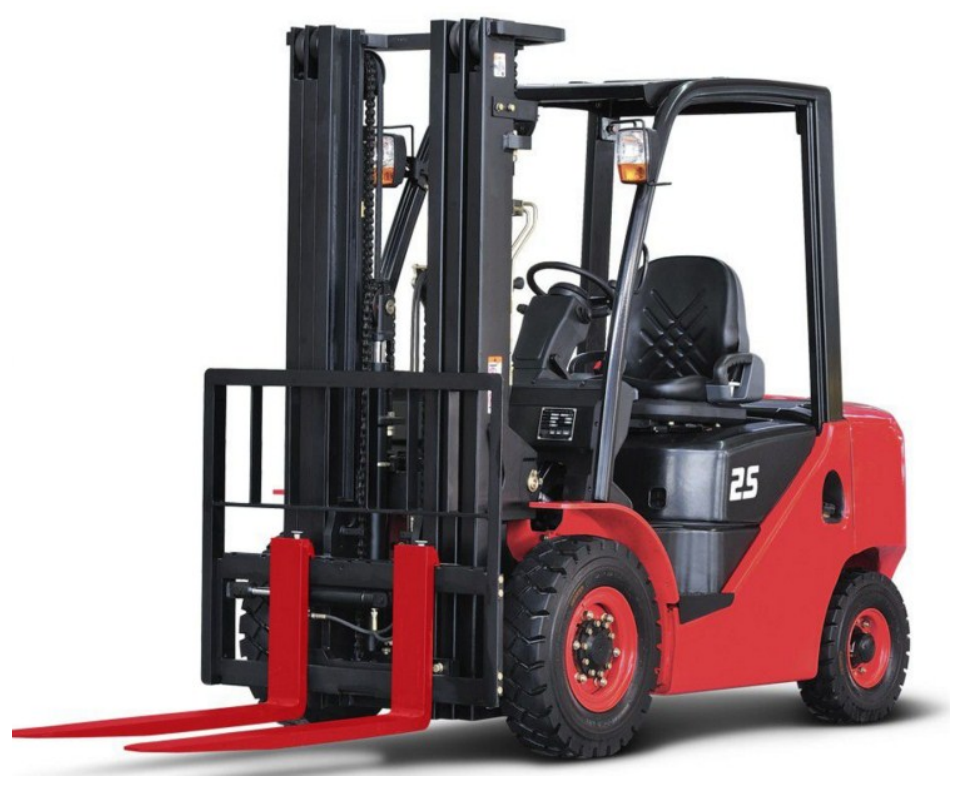

Figure 1 - Empilhadeira comum

No projeto "Proposta de sistema inteligente de definição de rotas para ambiente de armazenagem" de Rodrigo Neumann será feito um estudo sobre um dos algoritmos mais utilizados em pathfinding, o $\mathrm{A}^{*}$. Pathfinding é um método de determinação de rotas, comumente 
modelado na estrutura de grafos. Esse método se relaciona bastante com o veículo que será estudado nesse trabalho, uma vez que é de fundamental importância para o sucesso da aplicação de veículos autonomos, ou seja, sem a necessidade de um conductor. Para o uso efetivo dos AGVs é indispensável um sistema que faça a escolha da rota mais inteligente, ou seja, a mais curta e que não promova a colisão com outro veículo. Como dito anteriormente, esse sistema consiste em fazer um mapeamento através da estrutura de grafos, definindo as possíveis posições do veículo e os diversos obstáculos de um armazém, como paredes, estantes e maquinário.

No projeto "Modelagem, simulação e controle de um triciclo omnidirectional com motores independentes" de Thais Joffe sera apresentado um estudo teórico da cinemática plana e da dinâmica plana do veículo, sendo efetuada tanto a sua modelagem quanto a modelagem de seus motores. Ainda será abordada a implementação de um controle para realizar a variação de velocidade e direção das rodas do triciclo, analisando a influência dessas variações na velocidade final do veículo, na direção de seu deslocamento, na existência de derrapagem e nas limitações mecânicas em cada configuração. 


\section{Desenvolvimento}

\subsection{Chassi}

O chassi é a estrutura básica que recebe todos os outros componentes de um veículo e deve ser capaz de suportar todas suas cargas mecânicas. A rigidez de uma estrutura, que qualifica a sua deflexão sob carga, depende do seu material, da sua geometria e também do tipo de carga, e é um dos parâmetros mais importantes na hora de avaliar um chassi. Quando há deflexão excessiva, a rigidez da estrutura é insuficiente para resistir às cargas ou às sobrecargas operacionais elásticas, plásticas ou de fluência, e podem alterar a forma ou a estrutura a ponto de interferir na sua funcionalidade. Outro fator a se considerar é que a falta de rigidez pode alterar também as frequências naturais a ponto de causar ressonância sob cargas dinâmicas. No caso do veículo em questão, o chassi terá como função dar suporte aos três motores de esterçamento das rodas, ao sistema hidráulico responsável pelo levantamento da garra e a bateria. Assim, abaixo será feita uma descrição da disposição desses componentes no chassi desenhado e o por quê das escolhas feitas.

Para a concepção do chassi do veículo um dos pontos mais importantes foi o centro de massa. É sabido que a posição mais favorável do centro de massa do veículo em questão é o mais próximo ao solo, para que este tenha mais estabilidade. Tendo isso em mente, uma opção favorável nesse quesito seria a escolha por rodas com pequeno diâmetro, uma vez que por esse fato, o chassi e por consequência todos os outros componentes que integram o veículo estarão estar mais próximos ao solo. Outro ponto a ser considerado que tem relação direta com a localização do centro de massa é o contrapeso, componente típico das empilhadeiras comuns, utilizadas atualmente. Seu lugar ideal é sempre o mais afastado do mastro, uma vez que também levará o centro de massa para longe deste, produzindo assim um efeito positivo para garantir 
estabilidade dinâmica do veículo e sobretudo, possibilitará o mesmo a elevar cargas maiores, ou seja, aumentar sua capacidade.

Outro ponto a ser comentado é acerca dos motores de esterçamento. Na concepção do veículo, esses servomotores estarão dispostos logo abaixo das rodas, que terão sua direção determinada por uma estrutura em garfo ligada ao servomotor e ao eixo de cada uma delas. Como cada uma das rodas terá seu próximo motor de esterçamento e de tração, a disposição descrita acima será igual para as três rodas.

Pelo fato da bateria do veículo em questão ter um peso bem significante no peso total do veículo, cerca de $1 / 5$, foi necessário levar em consideração onde seria a posição favorável desse componente no chassi. O peso da bateria se relaciona diretamente com a sua voltagem, assim, a bateria de $48 \mathrm{~V}$ pesa aproximadamente $900 \mathrm{~kg}$, e baterias e menor voltagem serão mais leves, contudo $48 \mathrm{~V}$ é um valor plausível para a quantidade de horas de trabalho do veículo e pela quantidade de componentes que se utilizarão dela. É importante se atentar ao fato de que há uma diferença entre o peso da bateria quando ela está totalmente carregada e quando já foi utilizada e precisa de recarga, a medida que ela se descarrega seu peso vai diminuindo e por isso, deve-se levar em consideração o peso mínimo da bateria, por questões de precaução.

Tendo em mente a influência do peso da bateria em relação aos outros componentes do veículo é interessante dispô-la de maneira que contribua para a posição do centro de massa, no sentido de deixá-lo o mais próximo ao chão possível e pelo menos próximo a metade da distância entre as rodas. O ideal era que a bateria estivesse mais perto da roda única do veículo, para que a capacidade de levantamento do veículo pudesse ser ainda maior, contudo, para que o chassi não fosse maior que o necessário, o compartimento da bateria acabou por estar logo atrás das duas rodas. 
Abordados todos os aspectos da concepção do chassi do veículo omnidirecional, pode-se agora observar o desenho feito no software SolidWorks desse chassi, disposto na figura 2 (dois). Como pode-se perceber, é um modelo simplificado, com dimensões $1 / 1$ estimadas com base nos vários modelos já disponíveis no mercado de empilhadeiras e AGVs.

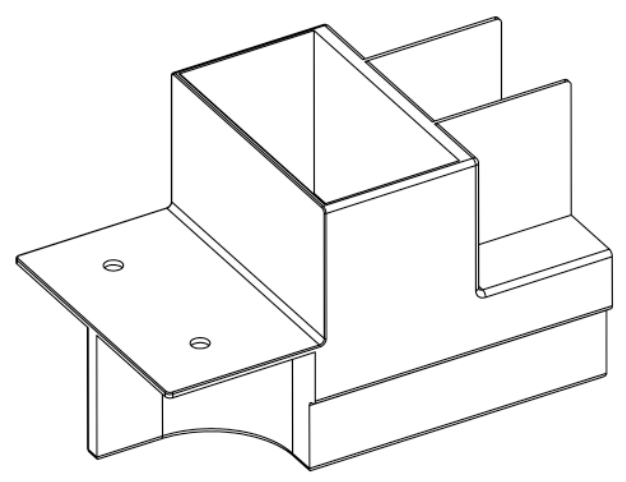

Figure 2 - Chassi 3D

A figura 3 (três) mostra as visões principais do desenho do chassi com suas dimensões. Como pode-se perceber, a proposta era deixá-lo o mais compacto possível para que seu peso não fosse excessivo. Com o intuito de determinar uma massa aproximada para o chassi, foi utilizada no software uma densidade aproximada do aço, material comumente utilizado para chassis, e assim, conhecendo o volume da peça, foi calculada uma massa de 4.000 (quatro mil) kg. Essa massa é compatível com as empilhadeiras usuais, para cargas não muito elevadas, da ordem de uma tonelada.
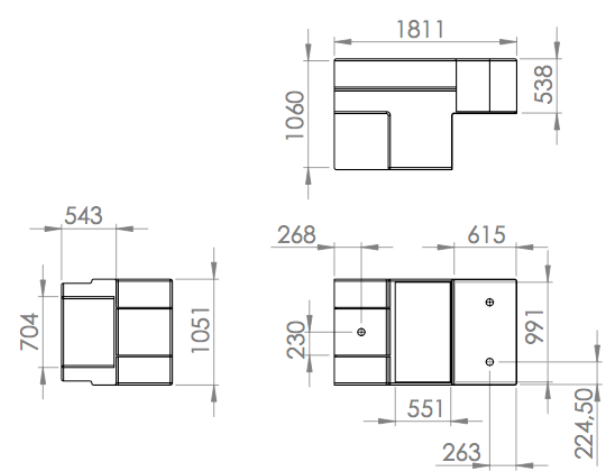

Figure 3 - Vistas do chassi 
Como já foi mencionado, o centro de massa é um dos aspectos que foi levado em conta no momento do desenvolvimento do modelo do chassi, assim, é importante apresentar seu posicionamento nos três eixos, que foi determinado também pelo software SolidWorks. Abaixo a figura 4 (quatro) está mostrado o posicionamento do centro de massa. A vista mais abaixo mostra a vista lateral do chassi, em que duas rodas juntas se encontram na esquerda. A vista mais acima é a vista superior do chassi e mostra que o centro de massa está localizado no eixo de simetria. Pode-se perceber que o centro de massa está posicionado próximo ao chão e mais próximo da roda única, que é uma posição bem favorável para a estabilidade dinâmica do veículo. Assim, conclui-se que o modelo proposto do chassi satisfaz esse quesito de modo plausível.

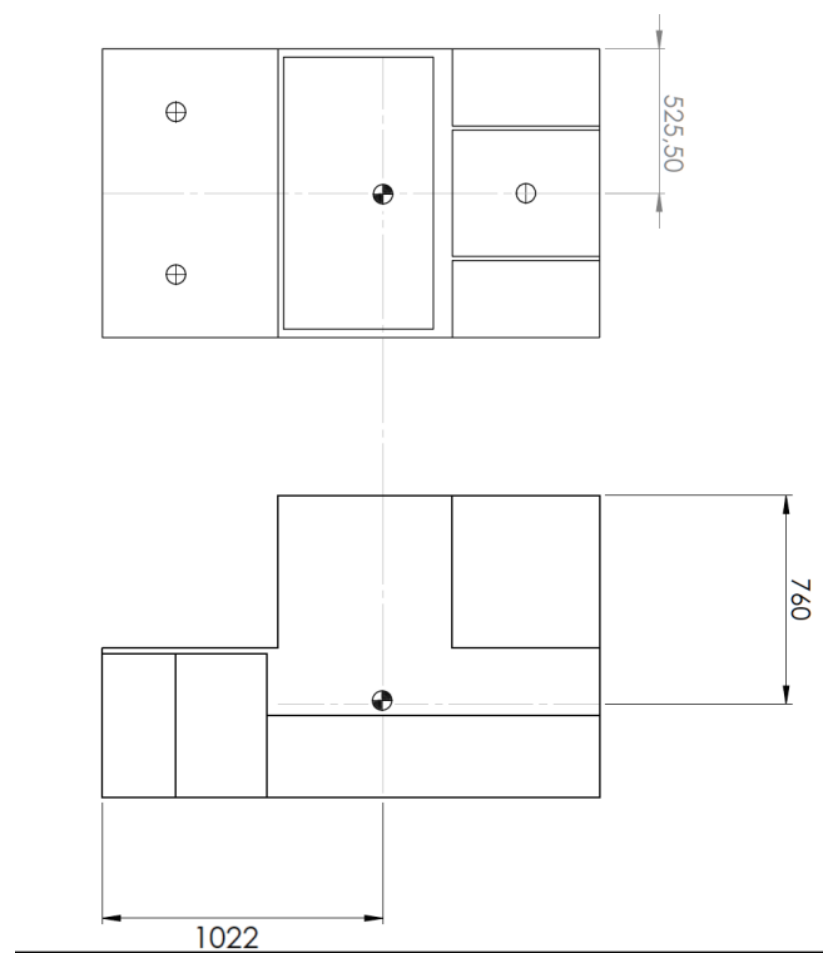

Figure 4 - Centro de massa do chassi

Apesar da figura acima mostrar o centro de massa do chassi, é necessário também determinar o centro de massa do chassi com os componentes que ele deve suportar, assim será possível uma localização mais realista do centro de massa do veículo como um todo. A partir 
dessa localização pode-se analisar a necessidade de um contrapeso. Observando a figura 5 (cinco) pode-se concluir que o objetivo de manter o centro de massa próximo ao chão foi bem sucedido, assim pode-se dizer que com os componentes adicionados ao chassi não houve prejuizos no posicionamento do centro de massa. Em relação a distância no eixo horizontal, o centro de massa está aproximadamente no centro do veículo, assim, o contrapeso pode ser uma boa opcão, que possibilitaria maior capacidade do veículo, que por si só está com uma massa plausível.

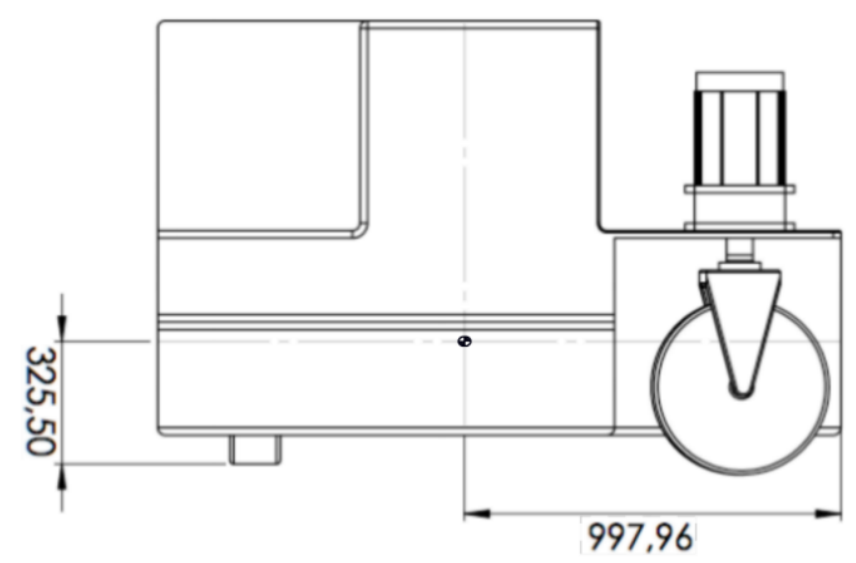

Figure 5 - Centro de massa do conjunto

Finalmente, a figura 6 (seis), disposta abaixo, permite ter uma visão mais geral do veículo como um todo, mais próxima a realidade, uma vez que todos os componentes já estão montados com o chassi.

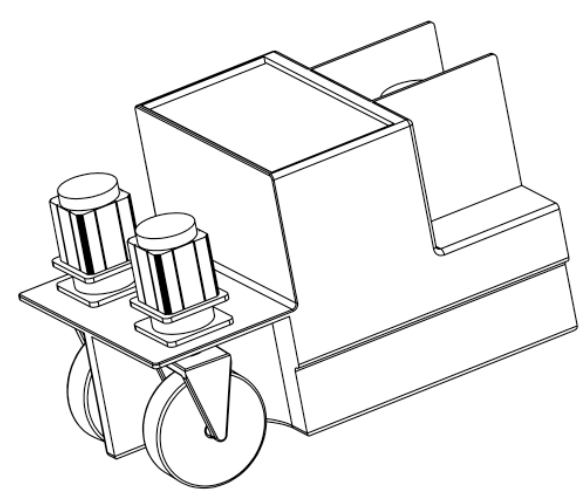

Figure 6 - Vista 3d do conjunto 


\subsection{Esterçamento}

Um veículo omnidirecional é aquele que executa movimento em todas as direções, possuindo 3(três) graus de liberdade, possibilitando o movimento nos eixos x e y, e em seu próprio eixo. Esse tipo de veículo se diferencia bastante daqueles que hoje são os mais comuns no mercado, porém essa tecnologia está se expandindo, principalmente pela sua grande aplicabilidade e conveniência nas áreas de robótica e de automação industrial. Atualmente os AGVs utilizam o sistema de direção baseado no princípio de Ackermann, e isso tem como consequência a grande dificuldade de manobrar esses veículos, e por isso é conveniente buscar alternativas, sendo uma delas o veículo omnidirecional. Para sua aplicação em armazéns para o transporte de cargas, esse tipo de sistema é benéfico, uma vez que torna possível sua movimentação em corredores mais estreitos e diminuindo consideravelmente o tempo da atividade, pela ausência de manobras complicadas.

Tendo em vista o objetivo de possibilitar que o veículo se movimente em todas as direções, uma possibilidade, e que foi escolhida para o veículo estudado nesse trabalho, é que o esterçamento das rodas seja produzido por um servomotor para cada roda. Este determinará a direção das rodas através da conexão com uma estrutura com forma de garfo, que estará acoplada a roda e ao motor. Sendo assim, pode-se concluir que no total, para a movimentação do veículo serão necessários três servomotores e três motores nas rodas. O ponto chave desse arranjo para a sua aplicação no veículo estudado é que ele permitirá que as três rodas do veículo sejam independentes entre si, ou seja, cada uma delas terá a uma velocidade e uma direção própria. Sabendo a velocidade e a direção das rodas separadamente não é de muita dificuldade determinar a velocidade e a direção do veículo como um todo. Apesar disso, esse sistema não é simples para fazer o controle e isso é um dos pontos negativos de sua aplicação. 
Na figura 7 (sete) está um desenho feito no software SolidWorks, que ilustra essa estrutura de garfo que deve ser utilizada juntamente ao servomotor para promover o esterçamento das rodas. $\mathrm{O}$ momento de inércia calculada diretamente pelo SolidWorks foi de $0.23 \mathrm{kgm}^{2}$, esse valor será um dos fatores que determinaram a potência necessária para o motor de esterçamento. Um fato que deve ser mencionado é que essa estrutura estará sujeita aos esforços na roda transmitidos pelo chão, assim é necessário uma análise acerca de sua resistência a esses possíveis esforços.

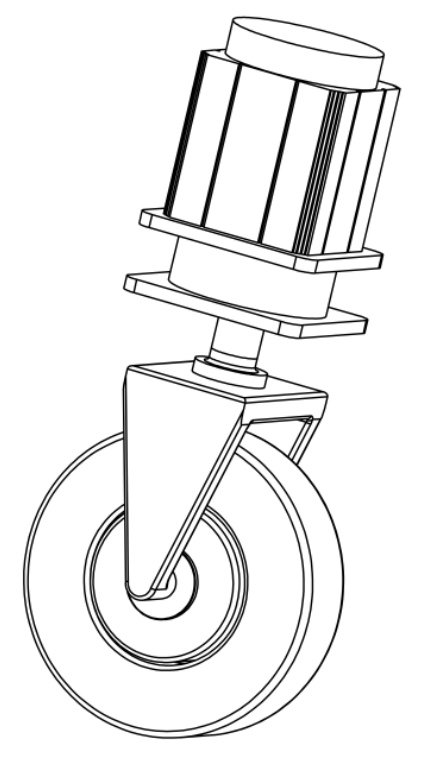

Figure 7 - Montagem dos componentes da roda

\subsection{Bateria}

Veículos elétricos, principalmente AGVs, normalmente utilizam como alimentação uma bateria chumbo-ácido. Esse tipo de bateria tem como composição básica chumbo, ácido sulfúrico em sua forma líquida e materiais plásticos. O anodo é o chumbo e o catodo é óxido de chumbo, ambos são placas retangulares dispostas alternadamente, com material isolante entre elas e submersas no eletrolito de solução de ácido sulfúrico. Esse tipo de bateria é muito interessante na 
aplicação do veículo estudado no presente trabalho pelo fato de ser recarregável e consideravelmente pesada, servindo como parte do contrapeso necessário para o veículo levantar as cargas.

Os AGVs utilizam como bateria como fonte de energia para sua movimentação. Assim sendo, é clara a necessidade de expor quais são as opções que envolvem a sua utilização. Como o tempo em que os veículos estão parados gera custos adicionais ao processo, a espera para que a bateria seja recarregada está fora de questão. Por isso as opções de troca de bateria abaixo descritas são alternativas viáveis:

A primeira opção, e mais intuitiva, é a troca de bateria feita manualmente por um operador. Após aproximadamente 8 horas de operação do veículo, o trabalhador remove a bateria usada e insere uma totalmente carregada no AGV. Essa opção tem como desvantagem a necessidade de um operador, porém o tempo necessário para a troca efetivamente não é muito longo.

A segunda opção, que é uma alternativa parecida com a opção acima, é a troca de bateria feita por uma máquina. Quando o AGV chegar a estação de troca de bateria, receberá uma bateria completamente carregada, enquanto a previamente utilizada será colocada para recarregar e só será utilizada novamente quando também estiver completamente carregada. A vantagem desse sistema é que não haverá a necessidade de um operador, e assim, tornando o processo mais seguro, entretanto a necessidade de uma maquina especial traz custos adicionais para o processo, além de eventuais necessidades de manutenção. Também se deve levar em consideração o espaço necessário para sua instalação.

A ultima opção é o recarregamento periódico, proporcionando que não haja a necessidade de troca da bateria. Esse sistema também considera o tempo em que o veículo tem a oportunidade de parar. Essa opção parece a menos desejada, uma vez que aparentemente o tempo de não 
funcionamento do veículo durante o dia será maior que em qualquer das outras opções. A facilidade desse método é que também não tem a necessidade de um operador. 


\section{Sistema de atuação}

\subsection{Servomotor}

O campo de aplicação dos servo-acionamentos vem crescendo cada vez mais, impulsionado pela necessidade de aumento da produtividade e da qualidade, e assim com a busca de máquinas cada vez mais rápidas e precisas. A aplicação de servomotores é vasta na automação industrial e isso se dá principalmente porque com ele é possível controlar a velocidade e a posição do eixo, além de obter um preciso controle do torque.

O servomotor é uma máquina síncrona, composta por um estator e um rotor. O rotor é móvel, e composto por ímãs permanentes Terras-Raras dispostos linearmente sobre sua face. $\mathrm{O}$ estator é uma parte fixa do servomotor, composto por seis polos de alimentação trifásica e sua função é promover corrente elétrica. Essa corrente no estator provoca o aparecimento de um campo eletromagnético, e esse campo se opõe ao campo existente no rotor. O resolver é um transformador de alta frequência, onde o primário se situa no rotor, e dois secundários no estator. É com o resolver que se pode determinar a posição e a velocidade do rotor, através das amplitudes e fases das tensões induzidas nos secundários.

Alguns cuidados devem ser tomados na aplicação de servomotores, para que seu funcionamento não seja comprometido. Deve-se atentar a umidade do ambiente em que o servomotor trabalhará, porque, uma vez exposto a umidade constante, pode ocorrer oxidação nas partes metálicas, degradação na fita que recobre os imãs do rotor e deteriorização do verniz isolante do estator. Todos esses fatores acarretam na redução da vida útil do servomotor. Outro ponto que se pode levar em consideração é a temperatura do ambiente. Idealmente o servomotor trabalha a 40o C, mas servomotores síncronos não têm muitos problemas com temperaturas elevadas, não necessitando de ventilação para refrigeração. Em compensação, temperaturas 
acima de 40o C podem ter como consequência a redução da potência, sendo como uma das formas de trabalhar acima da potência nominal a ventilação forçada.

O controle da posição do eixo é uma das funções mais importantes desse tipo de motor. Esse controle é do tipo malha fechada, que se caracteriza por um retorno do sinal, permitindo uma possível correção entre o sinal desejado e o obtido, a fim de minimizar o erro entre eles e caso haja mudanças ocasionadas por fatores externos, que esses sinais possam convergir novamente. O controle da velocidade do eixo é também função fundamental dos servomotores, porém esse controle não é muito fácil, principalmente por causa dos efeitos da inércia, da frequência de alimentação e de variações na temperatura.

A escolha de servomotores para a aplicação no veículo omnidirecional se justifica pela possibilidade de controlar a posição do eixo com grande precisão. Esse controle da posição é bem conveniente porque, sabendo que o servomotor será utilizado para o esterçamento das rodas, será possível controlar a direção da roda e com a junção de cada uma das direções pode-se obter a direção do veículo desejada. Felizmente, para o veículo estudado, a velocidade em que as rodas vão girar não é tão fundamental quanto o controle da posição do eixo, assim as fontes de erro mencionadas acima para a determinação da velocidade não afetaram de forma prejudicial o controle do veículo.

\subsection{Motor nas rodas}

A tecnologia de motor nas rodas, ou in wheel motor, é relativamente nova e se mostra como uma alternativa para os motores a combustão, vastamente difundidos atualmente. Diferentemente dos motores convencionais, esse tipo de motor é movido a eletricidade e é bastante compacto, podendo se localizar junto as rodas, e assim reduzindo o espaço que seria utilizado no chassi. Esse sistema de motor possibilita a independência das rodas do veículo e por isso é de grande interesse para o veículo proposto no presente trabalho, uma vez que para o 
movimento omnidirecional é necessário que as rodas possam se movimentos independentemente uma da outra. Além disso, o fato do veículo ser elétrico já introduz a necessidade de haver uma bateria como um de seus componentes, assim, possibilitando a alimentação desses motores sem grandes impactos na proposta inicial do veículo.

In wheel motor tem com uma das principais vantagens a eficiência energética, isso porque o fato do motor estar na roda elimina as perdas mecânicas que ocorrem quando o torque é transmitido por um eixo. O sistema desse tipo dotor já engloba diversos componentes necessários em um veículo, por exemplo, os freios, a suspensão, a transmissão, e por isso podese dizer que é uma alternativa bem compacta em relação aos motores a combustão. Outras vantagens do motor nas rodas é sua grande facilidade de manobra, possibilitando movimento que os sistema convencionais não são capazes de reproduzir e também promove grande estabilidade ao veículo.

A figura 8 (oito) ilustra um esquema do motor nas rodas. Como pode-se perceber, seu funcionamento se assemelha ao funcionamento de um motor elétrico comum, possuindo um estator e um rotor. Também pode-se perceber a presença de uma suspensão ativa como parte integrante desse sistema.

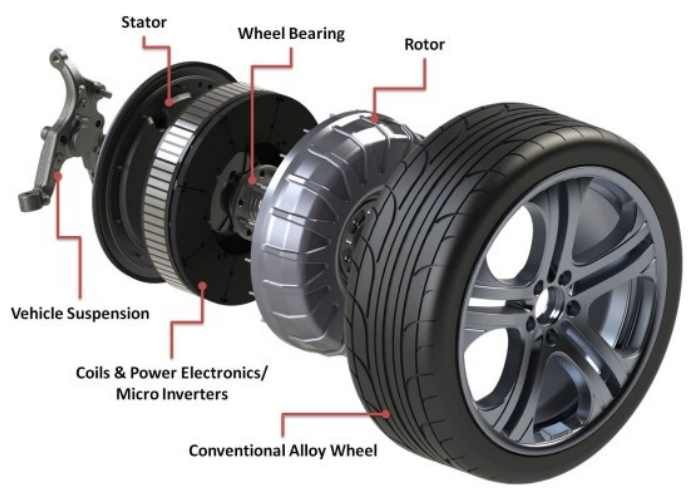

Figure 8 - Esquema do in wheel motor 


\section{Sistemas de navegação}

\subsection{Posicionamento relativo}

O método de posicionamento relativo ou dead reckoning consiste em determinar a posição atual do veículo com base em uma posição previamente conhecida e na medição da distância percorrida e da direção aplicada. Esse método tem como principal vantagem a sua simplicidade e foi utilizado a séculos para auxiliar as navegações marítimas. Hoje em dia já são utilizados dispositivos sofisticados porém mais a frente será mostrada possíveis falhas do procedimento.

Para estimar a distância percorrida se faz uso de um odômetro. Esse dispositivo determina a distância baseado na quantidade de rotações da roda, utilizando sensores tipo encoders. Erros sistemáticos do odômetro estão normalmente relacionados as rodas, seu alinhamento ou tamanhos levemente diferentes. Já para a determinação da direção do movimento, é utilizado um giroscópio, cujo funcionamento se baseia no princípio da inércia, podendo indicar mudanças na direção.

O fato do posicionamento relativo ser um método incremental, se em curtas distâncias o erro pode ser até desprezível, ele permite que para grandes percursos, a diferença entre o posicionamento real e o estimado seja consideravelmente grande. A Ausência de feedback permite erros cada vez maiores ao longo do tempo. Outro ponto que se deve comentar é que problemas na via como pequenos obstáculos podem comprometer ainda mais a exatidão desse método.

Por toda a análise feita acima, pode-se concluir que não é muito recomendada a utilização desse método unicamente. É interessante a escolha de alguma das soluções que abaixo estão dispostas e utilizar o método de dead reckoning para obter informação redundante. 


\subsection{Fita magnética}

Esse tipo de navegação consiste basicamente em criar caminhos com fita magnética, colados no chão do ambiente de trabalho. A fita magnética é adesiva, consideravelmente fina e flexível, sendo de custo bem baixo. Ela pode ser colada em qualquer tipo de material que não tenha componentes ferrosos. Em baixo do veículo é posicionado um sensor de campo magnético que garantirá que o veículo siga o percurso sem qualquer desvio, com boa precisão. Esse tipo de sensor será abordado mais a frente, no capítulo próprio de sensores, em que são detalhados seus mecanismos de funcionamento.

Esse sistema foi amplamente utilizado para várias aplicações, inclusive para a navegação de AGVs, no passado. As principais vantagens desse sistema de navegação são: Rápida instalação, baixo custo, boa precisão. Apesar da fita ser adesiva e poder ser mudada rapidamente, a determinação de rotas parece um fator limitante, resultando em uma falta de flexibilidade indesejada. Além disso, a necessidade de alteração do ambiente e a limitação do tipo de chão são os principais motivos para que hoje esse sistema esteja sendo substituído por outras tecnologias, mais flexíveis. Essa solução também não parece a mais conveniente para o veículo idealizado nesse trabalho.

\subsection{Pontos de referência magnéticos}

Esse método de navegação se utiliza de três informações principais para o controle do movimento e da posição do veículo. O primeiro componente é o odômetro que mede a distância percorrida de acordo com o giro do motor. O giroscópio também faz parte desse sistema e detecta as mudanças de direção do movimento sofridas pelo veículo. O que diferencia essa navegação da dead reckoning é que há uma terceira fonte de informação que permite que o 
sistema faça pequenos ajustes da rota, pequenos pontos magnéticos de referência no solo, que delimitam o caminho. Sensores magnéticos dispostos no veículo detectam esses pontos e com base na intensidade do campo magnético determinam a posição do AGV. O controlador tem como função analisar as informações recebidas e fazer os ajustes caso seja necessário.

Entre os benefícios do uso desse tipo de navegação pode-se citar: O sistema não precisa de manutenção; é aplicável facilmente em diferentes veículos; a exatidão do método permite que os veículos passem por corredores estreitos sem demais problemas; o sistema pode ser expandido sem necessidade de mudanças no ambiente.

Esse método parece satisfatório para a aplicação do mesmo em um veículo autonomo cuja função é transportar cargas em um armazém. Na verdade, ele já é utilizado para essa finalidade mas pode-se notar que os seus pontos fortes não são tão relevantes para aplicação proposta para o veículo estudado nesse trabalho.

\subsection{Navegação a laser (LGV)}

A navegação a laser é uma técnica de guiamento de navegação de veículos autônomos. Esse método de navegação consiste em posicionar diversos refletores no ambiente de navegação, como pontos fixos de referência e implantar um emissor/receptor laser no topo do veículo. O emissor/receptor laser, também conhecido como laser scanner, é um dispositivo que emite uma sequência de raios laser, com objetivo de medir a distância um objeto refletor. O laser scanner calcula a distância e o ângulo entre o mesmo e o refletor através do tempo decorrido e intensidade do raio detectado. Três pontos de referência são necessários para aplicar o princípio da triangulação e finalmente determinar a posição.

A implantação desse sistema como forma de monitorar e determinar a posição do veículo no ambiente tem como principais vantagens: Método seguro de medição de posição com boa 
precisão; sua instalação é relativamente fácil e não traz grande alteração ao ambiente; a expansão do sistema é feita facilmente.

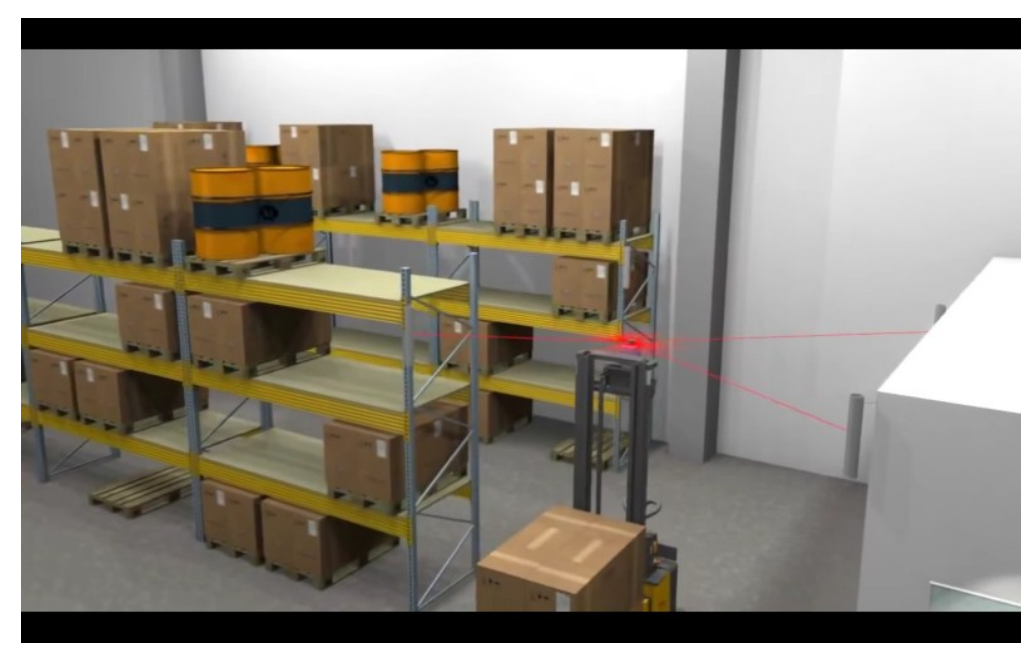

Figure 9 - Sistema de navegação a laser

A navegação a laser parece uma solução interessante para o veículo estudado no presente trabalho. O veículo autônomo proposto tem como ponto forte sua flexibilidade e facilidade de implantação no ambiente industrial e por isso a navegação a laser parece complementar esse ponto, também se mostrando bem adaptável a diversos ambientes e possibilitando o aumento da área de atuação do veículo sem comprometer o ambiente de armazenamento. Além disso, a precisão da posição é satisfatória para o propósito do veículo. A desvantagem de sua utilização é que ainda é uma tecnologia cara. É interessante analisar a possibilidade de acrescentar também o método de posicionamento relativo para que se faça uma verificação mútua entre os sistemas de navegação e proporcionar um posicionamento seguro e bastante confiável do veículo em questão. 


\section{Sensoriamento}

A utilização de sensores em ambiente industrial vem crescendo muito e a expansão da area de automação contribuiu bastante para o crescimento dessa tecnologia. O estudo do sensoriamento do veículo em questão é fundamental para seu funcionamento seguro.

Nesse capítulo, será feita uma exposição de diversos tipos de sensores com diferentes mecanismos de funcionamento. Todos os sensores abaixo apresentados podem ser aplicados no intuito de atender as diferentes necessidades do veículo estudado e assim para cada tipo de sensor será demonstrada a sua possível aplicabilidade no projeto proposto.

\subsection{Encoders}

Esse dispositivo é empregado em robótica para determinar posições por intermédio da rotação do motor que compõe o movimento da trajetória. O encoder é um transdutor que converte um movimento linear ou angular em pulsos digitais elétricos. Os pulsos gerados podem ser usados para determinar velocidade, taxa de aceleração, distância, rotação, posição ou direção.

Saber qualificar a posição ou movimento de um elemento as vezes se faz cruscial em procedimento industriais automatizados. Nessa área as aplicações dos encoders que podem ser destacadas são:

- Em máquinas ferramentas

- Em eixos de robôs

- Controle de velocidade e posição em motores elétricos

O sistema de leitura é baseado em um disco formado por janelas radiais transparentes e opacas alternadas. O disco é iluminado por um perpendicularmente por uma fonte infravermelha, 
que quando passa por uma janela transparente é projetada no receptor, que transporma em pulsos elétricos.

Há dois tipos de encoders disponíveis, que funcionam de maneira similar e utilizam o mesmo princípio das janelas opacas e transparentes.

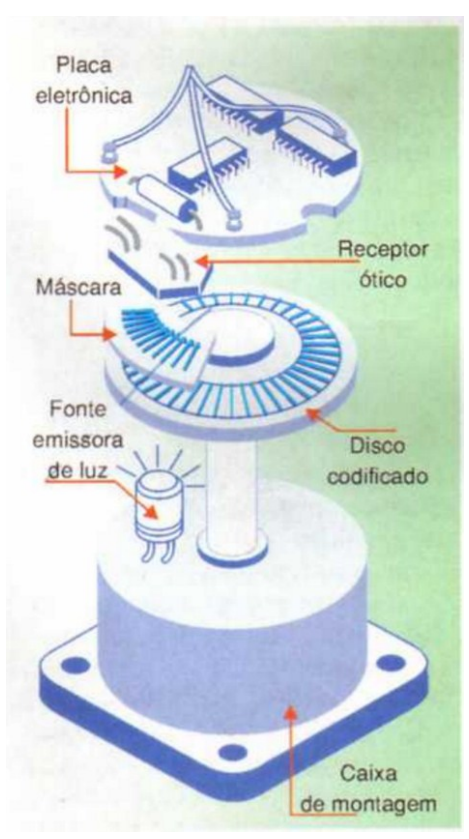

Figure 10 - Esquema de um encoder

Ao optar pela utilização de encoders deve-se levar em conta certas condições de trabalho que pode comprometer a precisão do dispositivo. Algumas indicações para o uso estão dispostas abaixo:

- A faixa normal de temperatura adequada para a utilização da maioria é de 0 a 70 graus Celsius.

- Caso o ambiente de trabalho seja úmido ou empoeirado, deve-se procurar um equipamento com selamento adequado para evitar contaminação. A contaminação do eixo-mancal compromete rapidamente a performance do encoder e também os componentes óticos. 
- O uso de microprocessadores e controladores pode criar um ambiente de trabalho com significativa quantidade de sinais elétricos, que podem gerar interferência eletromagnética.

Há dois tipos de encoders disponíveis, que funcionam de maneira similar e utilizam o mesmo princípio das janelas opacas e transparentes.

\subsubsection{Encoder Incremental}

Esse tipo de encoder normalmente fornece dois pulsos quadrados defasados de 90 graus, chamados canais A e B. A leitura de um dos canais vai fornecer a velocidade, enquanto a leitura dos dois canais fornece o sentido do movimento. O terceiro canal é o $Z$, que fornece a posição absoluta "zero". A resolução do encoder incremental é dada por pulsos/revolução, ou seja, um valor de pulsos elétricos a cada revolução do mesmo. Assim, quando se quer determinar a rotação mecânica é necessário apenas dividir a resolução por 360 graus. A precisão desse instrumento depende de alguns fatores tais como: excentricidade do disco, ou das janela; temperatura de operação; erros na leitura dos sinais elétricos.

\subsubsection{Encoder Absoluto}

O encoder absoluto tem o princípio de funcionamento bem parecido com o de um encoder incremental, assim, também é formado por um disco de janelas opacas e transparentes e um emissor de luz. O diferencial do encoder absoluto é que a posição dele é determinada pela leitura de um código e este é único para cada posição do seu curso. Isso permite que caso haja algum problema que ocasione no desligamento do encoder, quando ele funcionar novamente a sua posição será atualizada, diferentemente do método incremental. O código de saída 
empregado para determinar a posição normalmente é o binário, por causa de simplicidade de sua manipulação e não é necessário nenhum tipo de conversão para se obter a posição real do encoder.

\subsection{Sensores magnéticos (Efeito Hall)}

O efeito Hall foi exposto em 1879 por Edwin Hall. De acordo com seu experimento, concluiu-se que quando um circuito elétrico era submetido a um campo magnético, é gerada uma diferença de potencial. O sensor magnético consiste basicamente em uma placa retangular de um material semicondutor, que está ligada a um circuito. Quando há a presença de um campo magnético, os elétrons se movem para os lados da placa, criando uma diferença de potencial chamada A imagem abaixo ilustra o funcionamento desse tipo de sensor com mais clareza:

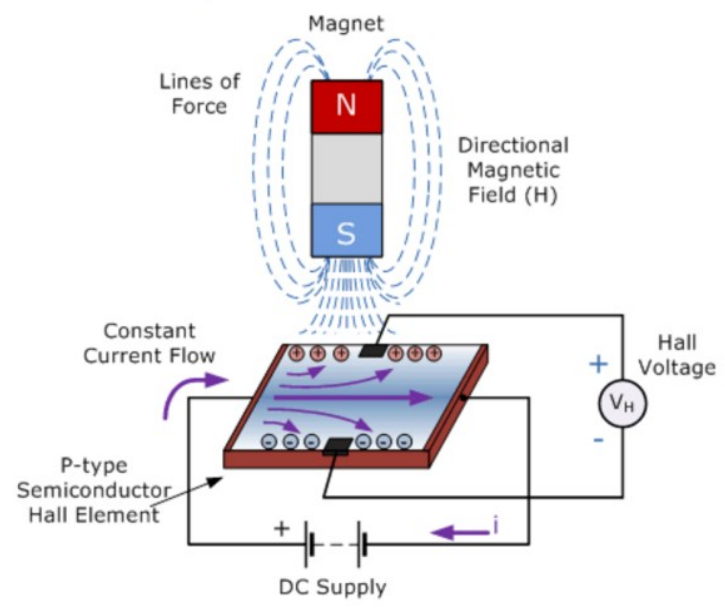

Figure 11 - Funcionamento do sensor de efeito Hall

No caso dos sensores para utilização da fita magnética, essas diferenças de potencial alertam que o veículo está se distanciando do centro da fita e assim possibilita a atuação para o ajuste da direção do AGV. As principais vantagens da utilização de sensores magnéticos são: Seu funcionamento não é debilitado quando estão sob condições indesejadas de trabalho, como 
ambientes empoeirados, úmidos, em altas temperaturas ou expostos a vibrações; podem ser utilizados como sensores de posição, sem a necessidade de contato físico com o objeto. A desvantagem mais obvia é que só funciona caso o objeto em questão.

\subsection{Sensores ultrasônicos}

Pelo fato de ser um veículo autônomo e de trabalhar no mesmo ambiente com semelhantes veículos, a necessidade de um sistema que evite a colisão entre eles é clara. Para essa função será proposta a utilização de sensores ultrasônicos em todo o seus redor, tendo ainda áreas de redundância. Além dessa função, os mesmo sensores terão como finalidade evitar possíveis acidentes com os eventuais trabalhadores que podem estar circulando no ambiente.

Esse tipo de sensor tem bastante aplicações industriais e na automação e é utilizado para detectar a proximidade de objetos. As facilidades que esse tipo de sensor trás são bem interessantes, como por exemplo: Não há restrição de material a ser detectado, como têm muitos outros sensores, são relativamente baratos e de fácil acesso; Pode detectar objetos sem necessidade de contato físico com o mesmo; entre distância de centímetros a metros; Não está sujeito a interferências eletromagnéticas.

Um sensor ultrassônico é basicamente composto por um emissor de ondas sonoras de alta frequência, além da faixa audível, e de um receptor, que recebe a onda refletida e converte em sinal elétrico. A determinação da distância entre o sensor e o objeto é feita pelo tempo em que a onda emitida retorna ao receptor. Há algumas disposições diferentes entre esses dois componentes, dependendo da sua aplicação, cabe fazer a escolha de qual é a disposição mais conveniente. Entre elas, tem-se: O emissor e o receptor um em frente ao outro, o emissor e o receptor um ao lado do outro e por último, essas duas funções em um único dispositivo. 
Sensores ultrassônicos podem também determinar se o objeto detectado está se aproximando ou se afastando. Isso é possível pelo fenômeno chamado Efeito Doppler, que consiste em uma mudança da frequência da onda quando é refletida por um objeto em movimento. No caso do objeto estar se afastando, a frequência refletida será menor que a emitida pelo sensor, e quando o objeto se aproxima a frequência refletida é maior que a emitida. Assim, basta medir a diferença entre essas duas frequências que é possível medir a velocidade do objeto. Esse fator é bem interessante para o veículo estudado nesse trabalho, uma vez que pode ser útil no caso de evitar colisões com outros veículo que estejam se aproximando.

Caso haja a adoção de sensores ultrassônicos para a aplicação desejada, é importante levar em consideração o ângulo de alcance do sensor. A curva para o range angular é tipicamente descrita como: Pequenos ângulos quando o objeto está muito próximo do sensor, a medida que vai se afastando esse ângulo cresce, até aproximadamente 30 graus, e a partir desse máximo, o ângulo vai caindo novamente. Na figura (numero) pode-se visualizar o bem o comportamento descrito acima:

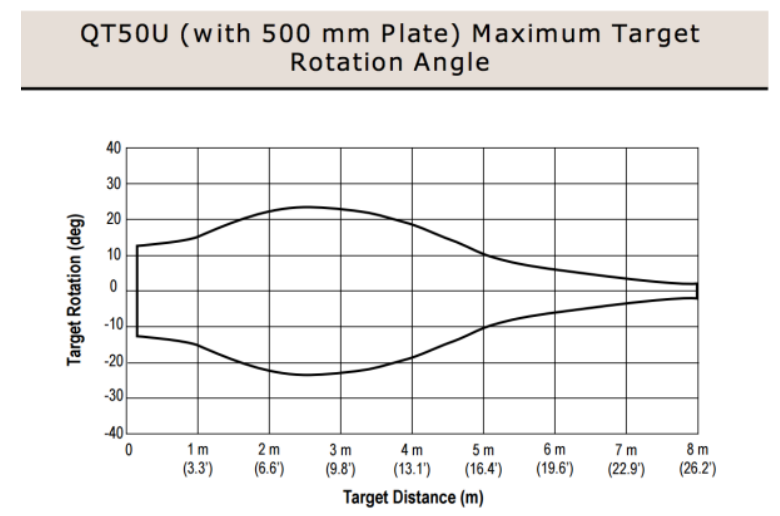

Figure 12 - Exemplo real do ângulo de alcance do sensor ultrassônico 


\section{Trabalhos futuros}

O projeto que engloba a concepção de um veículo de três rodas omnidirecional, com a função de transportar cargas em um armazém é bastante interessante e aos poucos já está sendo abordado em projetos reais de empresas especializadas veículos autônomos. Sendo assim, durante essa parte final do trabalho serão indicados outros estudos que podem ser feitos acerca do veículo em questão para que possa haver uma continuação desse projeto e que cada vez ele possa se tornar mais palpável.

É bastante interessante que se construa um modelo em escala do veículo proposto nesse trabalho, e as peças construídas no software SolidWorks permitem que essas sejam redimensionadas em escala. Esse modelo proporcionará uma visualização mais realista do movimento das rodas e por consequência determinar como o movimento do veículo está se dando, e caso haja interesse ainda se pode fazer seu controle com a tecnologia Arduíno, por exemplo.

Para produzir o movimento omnidirecional existem algumas soluções interessantes. $\mathrm{O}$ método utilizado nesse trabalho para o esterçamento das rodas e assim reproduzir esse movimento omnidirecional pode não ser o ideal. Assim, se faz a necessidade de avaliar se a estrutura de garfo é uma boa solução para esse problema, essa análise pode ser feita com o modelo em escala e com a análise dos esforços que essa estrutura esterá sob efeito.

Durante essa concepção, não foi abordado um estudo de grande importância, que é a análise dos esforços que o veículo pode estar submetido quando estiver no exercício de sua função. Pode ser feito até esse estudo com o método de elementos finitos, simulando por exemplo, o chassi sendo submetido a cargas verticais, ou em movimentos críticos, como em curvas e acelerações e desacelerações. Através dessa análise, a escolha do material para o chassi, 
assim como possíveis mudanças na sua geometria caso haja concentração de tensões em demasia.

Garantir a estabilidade dinâmica do veículo quando exposto a forças externas é necessário para o funcionamento adequado do mesmo, uma vez que caso esse aspecto seja deixado de lado diversos problemas podem advir, como exemplo o comprometimento da integridade do veículo e da carga transportada, gerando gastos inadequados. A análise da cinética é basicamente estabelecer relações entre forças externas atuando em um corpo rígido e como esse se comporta, ou seja, qual é o movimento resultante dessas forças. Para corpos rígidos, que pode ser considerado como um sistema de partículas, considera-se o movimento do seu centro de massa.

Um momento do movimento do AGV que pode ser considerado crítico é quando o veículo se encontra em repouso e a carga é levantada com uma aceleração para cima. É de fundamental importância a garantia de que o veículo durante esse movimento da carga não tombe para frente. Apesar do veículo proposto não ter necessidade de fazer curvas bruscas e em alta velocidade, pode ser interessante fazer uma análise da influência da força centrífuga no movimento. Outro momento que é fundamental levar em consideração na hora de analisar a estabilidade dinâmica do veículo é na frenagem. Duas são as possibilidades de ocorrer acidentes no momento em que ocorre uma desaceleração do movimento, sendo uma delas o veículo tombar para frente e a segunda a carga escorregar na garra. E por último, o veículo trafegando em uma via inclinada também pode ser considerado um momento crítico da cinética dos AGVs.

Uma outra sugestão para trabalhos futuros seria o desenvolvimento do sistema responsável pelo levantamento de carga. Atualmente, questões de espaço em armazém estão sendo resolvidas principalmente com a utilização de prateleiras umas em cima das outras. Por consequência, desenvolver um sistema adequado para cargas elevadas é fundamental para que a implantação do 
veículo proposto seja facilitada e abrangente. Determinações importantes para esse sistema seriam: Altura máxima do garfo; tipo de atuadores utilizados, material e forma da garra, com a preocupação principal de fadiga; como consequência a capacidade de carga do veículo. 


\section{Conclusão}

A tecnologia acerca dos veículos autônomos tem crescido bastante, principalmente na área de automação industrial. As vantagens da utilização desse tipo de veículo são visíveis quando os inserimos na tarefa de transportar cargas em um ambiente de armazenamento.

Durante esse trabalho foi possível determinar a viabilidade do veículo proposto, foram determinados os principais componentes necessários para sua concepção. Além disso, valores de mais importantes das peças, como o centro de massa e momento de inércia foram encontrados, baseados em valores próximos da realidade de densidade e massa. Em conclusão, os objetivos propostos nesse trabalho foram alcançados com sucesso, e para os novos estudos, a construção de um modelo em escala seria de muita utilidade para a continuação do projeto. 


\section{Bibliografia}

[1] Rodrigo Neumann - "Proposta de sistema inteligente de definição de rotas para ambiente de armazenagem" (Projeto de Graduação, 2015)

[2] Dr S.B.Rane, Harshal Shirodkar, P.Sridhar Reddy - "Finite Element analysis and Optimization of an Forklift Chassis" - 2013

[3] F.P. Beer e E.R. Johnston, Jr., "Mecânica Vetorial para Engenheiros. Estática, Cinemática e Dinâmica”, Volumes I e II, 5a Edição Revisada, Editora Makron Books, São Paulo, 1994.

[4] Mecatrônica Atual, "Manutenção de servomotores", 2013

[5] Mecatrônica Atual, "Servoacionamentos e servomotores”, 2013

[6] Mecatrônica Atual, "Sensores ultra-sônicos"

[7] TORE J LARSSON, JOHN LAMBERT, MARK WILDE, GUY TULLY, HOWARD ASKEW, WAYNE SKINNER, BARRY CARTER, TREVOR MARTIN, LANCE KENNINGHAM - "Industrial Forklift Trucks - Dynamic stability and the design of safe logistics"

[8] Castro.J.T.P e Meggiolaro.M.A.,” Iniciação de trincas- Vol I. “, 2009.

[9] NurulHuda Binti Muhamad Nasir - "Mechanical Design of an automated guided vehicle", 2006.

[10] Airtrax, "technical data sheet" do modelo Sidewinder ATX-3000

[11] Airtrax, "Maintenance Manual” do modelo Sidewinder ATX-3000

[12] Airtrax, "Parts Manual" do modelo Sidewinder ATX-3000

[13] Mecatrônica Atual No 31, página 32, 2006

[14] José Guilherme Santos da Silva, Francisco José da Cunha Pires Soeiro, Gustavo Severo Trigueiro, Marcello Augustus Ramos Roberto - “ANÁLISE ESTRUTURAL DE 
CHASSIS DE VEÍCULOS PESADOS COM BASE NO EMPREGO DO PROGRAMA ANSYS", 2001

[15] Curso “Mecânica automotiva” Disponível em:

$<$ http://www.cursosonlinesp.com.br/product downloads/v/mecanica automotiva 77855.pdf>

[16] "Hall effect Sensor" disponível em: $<\underline{\text { http://www.electronics- }}$ tutorials.ws/electromagnetism/hall-effect.html >

[17] Guidance navigation. Disponível em: < https://www.transbotics.com/learning-center/guidance-navigation> 